\title{
Exploration and spontaneous activity in young rats
}

\author{
ROBERT P. PALESE and PAUL M. BRONSTEIN \\ Brooklyn College of the City University of New York, Bedford Avenue and Avenue $H$ \\ Brooklyn, New York 11210
}

\begin{abstract}
Spontaneous-alternation behavior and activity levels of juvenile rats were measured during repeated 30-min exposures to a cross maze. Activity level increased as a function of age in animals 15-30 days old, but patterning of maze-arm choices was unrelated to maturation.
\end{abstract}

Young rats (approximately 16 days old) display higher and more persistent levels of activity in comparison to animals aged 3 weeks and older (Bronstein, Neiman, Wolkoff, \& Levine, 1974; Campbell, Lytle, \& Fibiger, 1969; Feigley, Parsons, Hamilton, \& Spear, 1972; \& Moorcroft, Lytle, \& Campbell, 1971). These findings might mean that the juvenile rat is highly exploratory (Williams, Hamilton, \& Carlton, 1975). However, Douglas, Peterson, and Douglas (1973) and Egger (1973) have demonstrated that juveniles, unlike adult rats, do not spontaneously alternate in a $T$ maze. Since alternation behavior has historically been explained within some exploratory context (see Dember \& Fowler, 1958; Glanzer, 1953; Walker, Dember, \& Earl, 1955), such results suggest that the heightened activity levels of the young rat may not represent exploration.

Jagoda and D'Amato (1960) and Montgomery (1952) have shown that in the absence of differentiating intramaze cues, rats aged 28 days and older show considerable response repetition. That is, they "explore that part of the maze . . occupied least recently (Montgomery, 1952, p. 57)." In an attempt to differentiate the development of walking from the ontogeny of exploration, the current experiment used Montgomery's definition of an in vestigatory response while also assessing the intensity of locomotion.

\section{METHOD}

\section{Subjects and Apparatus}

The subjects were 46 male and female Sprague-Dawley albino rats, 16 days of age at the start of the procedure, born and raised in the Brooklyn College colony. All animals were maintained with their mothers in plastic cages until 25 days of age at which time they were weaned and housed two to a cage (same-sex pairs); Purina lab chow and water were always available ad lib. The colony was illuminated $18 \mathrm{~h}$ /day ( 8 a.m. to 2 a.m.) with ambient temperature

This research was supported by Grant 10239E from the Research Foundation of the City University of New York. as well as by Grant MH 22027-01 from the National Institute of Mental Health to the second author. We are grateful to Rose Tichio for her help with the data analysis. Requests for reprints should be sent to Paul $\mathbf{M}$. Bronstein, Department of Psychology, Brooklyn College of the City University of New York, Brooklyn, New York 11210. fluctuating near $75^{\circ} \mathrm{F}\left(23^{\circ} \mathrm{C}\right)$. Two rats were chosen from each of 23 litters with one assigned to a longitudinal group which was tested. beginning on Day 16, every 3rd day until 25 days of age. The littermate was placed in a cross-sectional group, and tested at Day 25. All animals were observed again at 30 days of age.

A cross maze constructed of white Plexiglas was employed. This apparatus was fitted with a clear plastic top. The central choice area was $10.30 \mathrm{~cm}$ square and the four arms leading to the intersection were each $30.00 \mathrm{~cm}$ long. The entire maze was $10.30 \mathrm{~cm}$ wide and $10.20 \mathrm{~cm}$ high. Overhead lighting was provided by a 60 -W incandescent bulb shaded upward and suspended $134.07 \mathrm{~cm}$ above the choice point.

\section{Procedure}

Testing consisted of carrying each subject from the colony to the experimental chamber in a small plastic bucket, placing the rat into the southerly arm (facing the choice point) and observing its activity for $30 \mathrm{~min}$. The subjects which were tested only when 25 and 30 days old were removed from the litter for $30 \mathrm{~min}$ and placed into separate stainless steel cages (Wahmann, Model LC75/SA) while their littermates were tested. Thus, all animals run on Days 25 and 30 had received equal amounts of handling and maternal separation. Pup identities were established by marking with picric acid following the Day 16 procedures.

During the observation period, the experimenter manually operated two pushbuttons to record the duration of ambulation (defined as time spent walking or running), as well as the number of maze arms entered (tallied when the subject's whole body, except the tail, was in an arm). Latency to enter the first arm was also noted. These dependent measures were registered on separate clocks and counters (located in another part of the laboratory) for each $5 \mathrm{~min}$ of a trial. and the pattern of arm entries was recorded by the experimenter with pencil and paper. Finally, both walls and floors were wiped clean with dilute acetic acid (2\%-3\%) following a pup's removal so as to mask odor trails.

\section{RESULTS}

The reciprocals of each day's latency scores (initial arm-entry speeds) were analyzed with a repeatedtrials ANOVA for longitudinal animals and with correlated $t$ tests used to compare cross-sectional and longitudinal subjects. Hence, all statistical comparisons involved only $1 \mathrm{df}$ per litter (see Abbey \& Howard, 1973). These analyses revealed a reduction in latency of first arm entry during repeated testing, $F(4,110)=19.90, p<.01$. When tested at 25 days of age, longitudinal animals entered their first arm significantly sooner than control littermates, $t(21)=4.40, p<.01$. However, there was no significant difference between these two groups at 30 


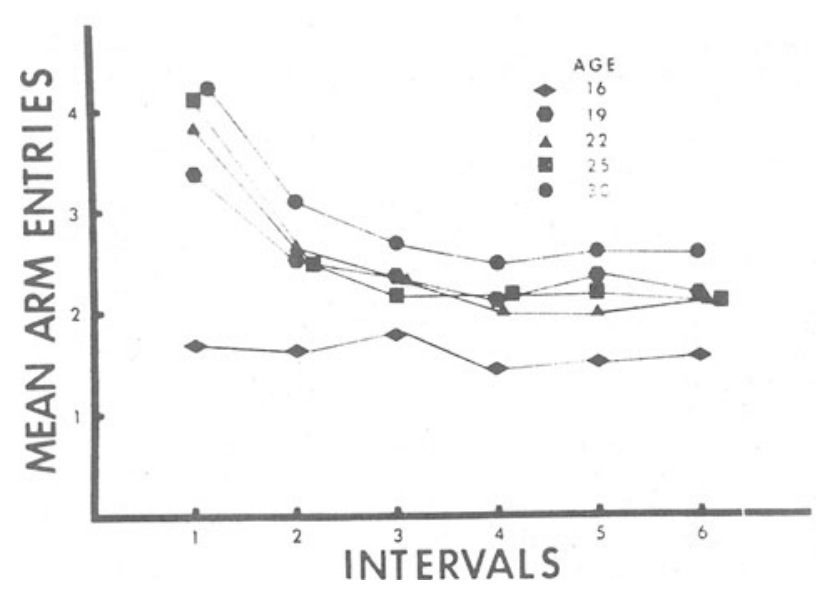

Figure 1. Mean number of mazearm entries per 5-min interval for longitudinal animals (16-30 days of age).

days of age, $t(21)=.602, p>.30$, since the cross-sectional subjects' latencies had decreased precipitously.

Duration of ambulation and transformed frequency of arm-entry score $(X+.5)^{1 / 2}$ were examined with an analysis of variance using the within-subjects variables of age and intratrial 5-min intervals (Bruning \& Kintz, 1968).

On both measures, the main effects of age and intratrial intervals as well as the Age by Intervals interactions were significant at the .001 level for the longitudinal animals. These results represented a reliable elevation of activity with increasing age along with significant habituation within a trial. The interaction emerged since only the 16-day-olds did not habituate; see Figure 1. There were no differences between the cross-sectional and longitudinal subjects on either Day 25 or Day 30, ts $(21) \leqslant .791$, ps $\geqslant .30$, with regard to ambulation and arm-entry scores.

Patterning of arm entries was described in several ways, with all of the following analyses conducted nonparametrically. None of the comparisons between repeatedly tested animals and their control (cross-sectional) littermates was significant.

First, maze-arm preference was analyzed. The percentage of total entries into each arm was calculated and it was revealed that during their initial exposure. longitudinal animals chose the northerly arm significantly less than on all subsequent tests, Wilcoxon Ts $(\mathrm{Ns}=23) \geqslant 64$, ps $\geqslant .05$. There was no significant difference on this measure between cross-sectional animals when tested on Days 25 and 30.

Second, the relative frequency of all directional movements was determined. The four possible responses at the choice point were: (a) right turn, (b) left turn, (c) straight ahead, and (d) returning into the arm from which the subject had just emerged. For both longitudinal and cross-sectional animals and during all exposure trials, there were significantly fewer returns than any other response, $\chi^{2} s(a) \geqslant 16.62$, $p \geqslant .01$. There were no significant differences in the occurrence of the other three turn choices, $\chi^{2} s(3) \leqslant 2.85$, ps $\geqslant .10$. Furthermore, there was no more than a $4 \%$ day-to-day fluctuation in the relative frequency of any of the four responses.

Third, directional responses were analyzed sequentially by partitioning into running pairs each subject's string of responses for each day. For example, in the following series of responses: right-right-left-straight ahead-return, the first two responses (right-right) comprised one pair; the next two responses (right-left) made up a second pair; a third pair was composed of the ensuing two directional movements (left-straight ahead); and the last two responses (straight ahead-return) was a fourth pair. The second, third, and fourth of these couplets would be alternations. Alternation percentages, as described in Jagoda and D'Amato (1960), were calculated daily for each animal. This percentage was defined as the ratio formed by the number of response alternations in a subject's daily sequence divided by the number of responses in that sequence, minus one. There was no significant change in this variable over repeated exposures to the apparatus, Friedman $\chi^{2} r(4) \leqslant .759, p \geqslant .90$. Animals tested only on Days 25 and 30 also did not differ from each other on this measure as determined with the sign test. Alternation percentages for both cross-sectional and longitudinal animals on any given day varied only from $62 \%$ to $69 \%$.

\section{DISCUSSION}

The present experiment replicates earlier findings showing 15to 16-day-old rats to be persistent in their locomotor activity. We also confirm Goodrick's (1974) work which showed the intensity of activity to be lower among 15-day-olds than in older rats. Several investigators (e.g., Campbell et al., 1969; Feigley et al., 1972; Moorcroft et al., 1971) have noted that the absolute levels of rats locomotor activity vary as a function of age, but in a manner other than that reported here. The procedural details which might be responsible for this variability are not yet understood.

Further, the current study suggests that the changes both in absolute level of activity as well as in the persistence of locomotion among the different age groups are not indices of exploration when investigative responses are defined as entries into a relatively novel maze arm. With the exception of the reliable increase in choice of the northerly arm in the older groups, no consistent age-related changes in position preference, turn preference, or response alternation were noted. It seems that young rats, although the characteristics of their locomotion may be unique, do not explore any differently than older subjects.

Finally, it is unclear why, in the current work, alternation was unrelated to age. Discrete-trial procedures of assessing spontaneous alternation uniformly have shown increasing rates of alternation between Day 15 and Day 30 (cf. Bronstein. Dworkin, \& Bilder. 1974). The somewhat unique apparatus of the present experiment as well as the absence of handling our subjects between trials should be noted when comparing the current results to those gathered by other investigators. 


\section{REFERENCES}

Abbey, E., \& How ARD. E. Statistical procedures in developmenta studies with multiple offspring. Developmental Psychobiology. 1973. 6. 329-335.

Bronstein, P. M.. Dworkin, T., \& Bilder, B. H. Age-related differences in rats spontaneous alternation. Animal Learning \& Behavior, 1974, 2, 285-288.

Bronstein. P. M., Neiman, H., Wolkoff, F. D., \& Levine. M. J. The development of habituation in the rat. Animal Learning \& Behavior, 1974, 2, 92-96.

BRUNING, J. L., \& KinTz, B. L. Computational handbook of statistics. New York: Scott, Foresman, 1968.

Campbell, B. A., Lytle, L. D., \& Fibiger, H. C. Ontogeny of adrenergic arousal and cholinergic inhibitory mechanisms in the rat. Science, 1969, 166, 635-636.

DEMBER, W. N., \& Fowler, H. Spontaneous alternation behavior. Psychological Bulletin. 1958, 55, 412-428.

Douglas. R. J.. Peterson, J. J., \& Douglas, D. P. The ontogeny of a hippocampus-dependent response in two rodent species. Behavioral Biology, 1973, 8, 27-37.

EGGER, G. T. Novelty induced changes in spontaneous alternation by infant and adult rats. Developmental Psychobiology, 1973. 6. 431-435.

Feigley, D. A.. Parsons, P. J., Hamilton, L. W., \& SPEAR, N. E. Development of habituation to novel environments in the rat. Journal of Comparative and Physiological Psychology', 1972. 79. 443-452.
Glanzer. M. The role of stimulus satiation in spontaneous alternation. Journal of Experimental Psichology, 1953, 45. 387-393.

Goodrick. C. L. Exploration activity of immature albino rats. Developmental Psychobiology, 1974. 10. 438-441.

JaGoda. H.. \& D'Amato, M. R. Response repetition in a tree-responding situation. Journal of Comparative and Physiological Psychology. 1960, 53, 264-266.

Montgomery, K. C. Exploratory behavior and its relation to spontaneous alternation in a series of maze exposures. Journal of Comparative and Physiologiral Psychology. 1952. 45, 50-57.

Moorcroft, W. H., Lytle, L. D., \& Campbell, B. A. Ontogeny of starvation-induced behavioral arousal in the rat. Journal of Comparative and Physiological Psychology. 1971, 75. 59-67.

SIEGEL, S. Nonparametric statistics for the behavioral sciences. New York: McGraw-Hill, 1956.

Walker, E. L.. Dember, W. N.. \& Earl. R. W. Choice alternation: 1. Stimulus vs. places vs. response. Journal of Comparative and Physiological Psychology, 1955, 48, 19-23.

Williams, J. M.. Hamilton, L. W., \& Carlton, P. L. Ontogenetic dissociation of two classes of habituation. Journal of Comparative and Physiological Psychology, 1975. 89. 733-737.

(Received for publication January 5, 1976.) 